\title{
Using Personality to Predict Outbound Call Center Job Performance
}

\author{
Pamela Skyrme \\ Skyrme \& Associates, Inc. \\ Lisa Wilkinson \\ University of South Florida
}

\author{
Joseph D. Abraham \& John D. Morrison, Jr. \\ A\&M Psychometrics, LLC
}

This study investigates the usefulness of the Big Five personality variables, as measured by the Performance Perspectives Inventory (Abraham \& Morrison, 2002), in predicting objective measures of employee productivity and subjective measures of training performance in an outbound call center. We found that Conscientiousness, Emotional Stability, and Agreeableness correlated significantly with productivity of incumbent outbound call center representatives. Additionally, Conscientiousness, Emotional Stability, Extraversion, and Openness to Experience correlated with new hire training performance.

Reviewers of the technique's history have referred to the period leading up to the 1980's as the “...Dark Days of Personality Testing in Industry” (Lodato, Zickar, \& Fuller, 2004). In particular, prevailing skepticism concerning the use of personality measures in selection marked the 1960's and 1970's. Doubts largely stemmed from inconsistent validity evidence, as well as lack of consensus regarding the underlying structure of personality or appropriate performance criteria (Ghiselli, 1973; Guion \& Gottier, 1965; Schmidt, Gooding, Noe, \& Kinch, 1984). The Five Factor Model's (i.e., Big Five) emergence as a widely accepted taxonomy of normal personality in the ensuing decades has helped address many of the skeptics' concerns. By serving as a guide for organizing research findings and framing hypotheses, the model has enabled researchers using meta-analysis to shed new light on the relationships between personality characteristics and job performance (e.g., Barrick \& Mount, 1991; Mount \& Barrick, 1995; Hogan \& Holland, 2003). The validity of the Big Five personality factors has been evaluated for a number of job groups, including managerial, sales, customer service, skilled, and semi-skilled roles (e.g., Barrick \& Mount, 1991; Hurtz \& Donovan, 2000). Nevertheless, a search of the relevant literature indicates that little published research has investigated the validity of the Big Five in predicting performance for the specific role of outbound call center representative. The present study is a criterion-related validation study of the Big Five factors of personality on an outbound call center job using two criteria, employee productivity and training performance, in two independent samples.

The Big Five taxonomy of personality proposes five factors to encompass personality: extraversion (outgoing, motivated, adventure-seeking, and optimistic), 
emotional stability (without anxiety, insecurity, despondency, and belligerence), conscientiousness (trustworthy, detail-oriented, driven, and organized), openness to experience (innovative, nonconformist, flexible, and open-minded) and agreeableness (friendly, dependable, helpful, and cooperative). Support for the use of the Big Five in selection comes from a number of meta-analyses (see Barrick, Mount, \& Judge, 2001) that have consistently found relationships between the Big Five and various performance measurements (supervisor ratings, training proficiency, attendance, productivity, etc.).

For example, Salgado (1998) found that conscientiousness and emotional stability explained $12 \%$ and $7 \%$, respectively, of variance in performance ratings beyond that of cognitive ability. While consistent and strong relationships between cognitive ability and performance across a wide range of jobs have been shown (Schmidt and Hunter, 1998), it is useful to identify non-cognitive variables that can predict variance beyond that of cognitive ability tests. Salgado's (1998) findings demonstrate the usefulness of personality as a selection tool to complement cognitive ability in predicting performance. Further support for the use of the Big Five personality factors in selection provided by Salgado (2003). Salgado found that instruments designed around the five factor model of personality had greater criterion validity than non-five factor model personality instruments. These two studies underscore the potential usefulness of the Big Five in selection contexts.

In the present study, the Performance Perspective Inventory (PPI, Abraham \& Morrison, 2002) was used to measure the Big Five. Because this instrument was developed for the purpose of selection, it avoids the psychological language used in some more clinically-oriented personality inventories that might not translate well to workplace settings. Therefore, it was well accepted by the organization sponsoring the validation study as part of a major revision to their outbound call center selection system. Further, there is support for the construct and criterion-related validity of the PPI. For example, construct validity is supported via strong convergent relationships with similar constructs from the NEO-PIR (Costa \& McCrae, 1992) and other instruments (Abraham \& Morrison, 2002). Correlations between the five dimensions of the PPI and corresponding NEO-PIR scales ranged from .65 to .85.

The criterion-related validity of the instrument is supported by a number of studies (Abraham \& Morrison, 2002; Abraham \& Morrison, 2003a; Abraham \& Morrison, 2003b; Morrison \& Abraham, 2003; Morrison, Abraham, \& Dennis, 2004), two of which will be described here. Morrison, Abraham, and Dennis (2004) found that conscientiousness correlated significantly with gross revenue, profitability, and labor costs for restaurant managers, and openness to experience correlated significantly with gross revenue. Similarly, Abraham and Morrison (2003a) found that conscientiousness was significantly correlated with supervisor ratings of security guard performance. These studies demonstrate the predictive ability of the PPI. Further, the scale reliabilities for the five dimensions are acceptable (Abraham \& Morrison, 2002) with internal consistency ranging from .78 to .85 and test-retest reliabilities ranging from .86 to .92 . Consequently, the applicability of the instrument to the workplace and the psychometric properties of the scale support the use of this measure for the present study. 
The criterion validity studies described above demonstrate that not all of the Big Five personality factors are equally successful at predicting performance across positions and criteria. This is consistent with existing meta-analytic research on the Big Five. Meta-analyses have found that conscientiousness and emotional stability predict performance across a wide range of jobs (e.g., Mount \& Barrick, 1995). However, the three remaining factors (extraversion, openness to experience, and agreeableness) have been found to correlate significantly with performance in different occupations and with different criteria. For example, extroversion has been found to correlate with sales and managerial job performance, and agreeableness and openness to experience have been found to correlate with customer service job performance (Hurtz \& Donovan, 2000).

\section{Hypotheses}

As mentioned previously, the present study investigates the use of a personality measure for selection in an outbound call center job. Our job analysis results indicated that this job involves a great deal of interpersonal interaction, as incumbents are required to recruit research participants over the telephone. Mount, Barrick, and Stewart (1998) performed a meta-analysis of the relationship between personality and performance on jobs that involve a significant amount of interpersonal interaction. These authors found that all five of the Big Five variables were significantly related to supervisor ratings of job performance, but that agreeableness, emotional stability, and conscientiousness were the strongest predictors $(.22, .18$, and .26, respectively). Therefore, although the primary on-thejob criterion for the present study was an objective measure of employee productivity rather than supervisory ratings of performance, we expected that conscientiousness, emotional stability, and agreeableness would predict the performance of outbound call center employees.

The second type of criterion used in the present study is training performance. At least two meta-analyses have looked at personality and training proficiency. Barrick and Mount (1991) found that extroversion, openness to experience, and conscientiousness were significant predictors of training proficiency. Hurtz and Donovan (2000) found that extraversion and agreeableness were most strongly related to training proficiency (.17 and .18, respectively) and that conscientiousness had a non-significant relationship (.03) with training proficiency. There were only four studies included in the training proficiency analyses done by Hurtz and Donovan, whereas with Barrick and Mount meta-analysis included, at minimum, 14 studies. Thus, the results found by Barrick and Mount appear more reliable than the results found by Hurtz and Donovan. Therefore, it is predicted that extroversion, openness to experience, and conscientiousness will be related to training performance in the current study.

\section{Methods}

\section{Participants}

Data were collected from two independent samples. Subjects in the first sample were current job incumbents and subjects in the second sample were new 
hires. The subjects in this study were research interviewers, working in an outbound call center environment. Their task is to engage callers to a degree that they agree to participate in a research study. Subjects are trained for 10 days immediately upon hire and then begin calling in a 'real-time' environment.

In the first sample $(n=399)$, subjects were experienced incumbents ranging in age from 17 to 82 . Twenty-six percent were men and $74 \%$ were women. Job tenure ranged from several months to 16 years. Subjects were from the following racial/ethnic groups: White 70 \%; African American 8 \%; Hispanic/Latino 20\%.

For the second (training) sample ( $\mathrm{n}=93)$, subjects were new hires ranging in age from 22 to 67 . Thirty-nine percent of the subjects were men and $61 \%$ of the subjects were women. Subjects were from the following racial/ethnic groups: White 65\%, African American 7\%, Hispanic/Latino 28\%.

\section{Objective Performance Measure}

Objective job performance was collected from a company database on each subject and was calculated as the number of accepts divided by the number of accepts plus the number of refusals. Accepts are the number of people who have agreed to participate in the research study and refusals are the number of people who have declined to participate in the research study.

It was determined through discussion with the sponsoring company that a minimum of 250 calls was required per calling cycle to provide an adequate range of types of calls, and to provide an opportunity to obtain an accurate measure of the subject's 'true' performance. Therefore, all analyses were limited to job incumbents with at least 250 calls during the time period analyzed. Forty participants were excluded based on this criterion, reducing the sample size to 359. Note that when the entire sample was used, the correlations of the personality measures with performance showed the same pattern reported below, but the correlations were smaller in magnitude.

\section{Performance Perspective Inventory (PPI)}

Three hundred and ninety-nine incumbents and 93 new hires completed the PPI. The PPI is a 155 item instrument that measures the Big Five components of personality and 22 subscales. Each item is rated on a five-point scale ranging from very inaccurate to very accurate. The five major scales (i.e., Big Five) demonstrated good internal consistency in the present study, ranging from .69 to .89, in both samples (see Tables 1 and 2 for these results). The test was administered over the web in a proctored environment, with standardized instructions and conditions, and took approximately 20 minutes, on average, to complete. For more information on the PPI, readers are directed to Abraham and Morrison (2002).

\section{Training Scores}

Training ratings were provided by trainers who rated each new hire at the end of the 10 days of training. Trainers were provided with the rating forms which included behaviorally anchored rating levels and definitions of the dimensions. Each trainer provided an independent rating on each new hire. Once these ratings were completed, a consensus discussion ensued. Once a consensus rating was reached it 
was recorded on a summary form. These consensus ratings constituted the final rating for each dimension for each new hire. Nine dimensions were rated: Attendance/Punctuality, Class Participation, Voice Skills, Coding, Probing and Clarifying, Persuading, Personality, Advanced Strategies, Overall Rating. These dimensions were developed through discussion with the trainers, by reviewing other available daily rating forms, and by reviewing quality monitoring forms used on the job. Ratings were made on a five point scale ranging from significantly above target to significantly below target.

\section{Results}

\section{Productivity Criterion}

The intercorrelations among the personality variables are displayed in Table 1 and the criterion-related validity coefficients and PPI descriptive statistics are displayed in Table 2. As predicted, conscientiousness $(r=.23, N=359, p<.01)$, emotional stability ( $r=.22, N=359, p<.01)$, and agreeableness $(r=.15, N=359, p$ $<.01$ ) were all significantly correlated with the objective measure of productivity.

\section{Training Performance}

There were nine (9) variables included as criteria for measuring training performance. Each of the Big Five factors correlated with at least one measure of training performance, displayed in Table 3. It was predicted that conscientiousness, extroversion, and openness to experience would predict training performance. As can be seen in Table 3, the prediction was supported.

Table 1

Intercorrelations among predictor variables

\begin{tabular}{lcccc}
\hline Variable & 1 & 2 & 3 & 4 \\
\\
\end{tabular}

Note: ** Correlation is significant at the 0.01 level (2-tailed). 
A factor analysis was performed to determine if the training dimensions could be combined for further analysis (Table 4 displays the zero-order correlations among the training variables). A promax oblique rotation was utilized, which would allow the factors to be correlated. The results showed that attendance loaded on one factor and the remaining training variables loaded on the other factor (see Table 5 for the loadings and eigenvalues). Based on these factor analysis results, we summed the eight training dimensions (excepting attendance) to create a composite score indicative of performance in training. The internal consistency of the training performance composite was $89(N=81)$.

Table 2

Correlations with acceptance percent

\begin{tabular}{lcccc}
\hline \multirow{2}{*}{ Variable } & \multicolumn{2}{c}{ Descriptive Statistics } & \multirow{2}{*}{ Reliability (Alpha) } & $\begin{array}{c}\text { Correlation with } \\
\text { Acceptance Percent }\end{array}$ \\
\cline { 2 - 4 } Agreeableness & 4.20 & .40 & .78 & $.15^{* *}$ \\
Conscientiousness & 4.29 & .43 & .86 & $.23^{* *}$ \\
Extraversion & 3.72 & .52 & .69 & .09 \\
Openness to experience & 3.92 & .53 & .78 & .09 \\
Emotional stability & 1.10 & .42 & .83 & $.22^{*}$ \\
Acceptance percent & 0.51 & .11 & & \\
\hline
\end{tabular}

Note: Acceptance percent $=$ accepts $/($ accepts + refusals $)$

$* p<.01$

Table 3

Correlations between PPI and training measures

\begin{tabular}{|c|c|c|c|c|c|c|c|}
\hline \multirow[b]{2}{*}{ Training Measures } & \multicolumn{2}{|c|}{$\begin{array}{c}\text { Descriptive } \\
\text { Statistics }\end{array}$} & \multicolumn{5}{|c|}{ PPI Dimensions } \\
\hline & Mean & (SD) & Agreeable & Conscientious & Extraversion & $\begin{array}{c}\text { Emotional } \\
\text { Stability }\end{array}$ & $\begin{array}{c}\text { Openness to } \\
\text { Experience }\end{array}$ \\
\hline $\begin{array}{l}\text { Attendance/ } \\
\text { Punctuality }\end{array}$ & 3.44 & .94 & -.00 & .04 & -.20 & .13 & -.16 \\
\hline Class Participation & 2.95 & .85 & $.33^{* *}$ & $.39 * *$ & $.28 *$ & $.31 * *$ & $.36^{* *}$ \\
\hline Voice Skills & 3.06 & .56 & .12 & .12 & $.29 * *$ & .15 & $.35^{* *}$ \\
\hline Coding & 3.09 & .82 & .07 & .21 & .12 & .13 & $.23^{*}$ \\
\hline $\begin{array}{l}\text { Probing \& } \\
\text { Clarifying }\end{array}$ & 3.07 & .58 & .04 & .22 & .03 & .17 & $.33 * *$ \\
\hline Persuading & 2.98 & .59 & .20 & $.22 *$ & $.31 * *$ & $.29 * *$ & $.44^{* *}$ \\
\hline Personality & 3.13 & .54 & .12 & .20 & $.23^{*}$ & $.22 *$ & $.31^{* *}$ \\
\hline $\begin{array}{l}\text { Advanced } \\
\text { Strategies }\end{array}$ & 3.15 & .57 & $.25^{*}$ & .19 & .11 & .14 & .19 \\
\hline Overall Rating & 3.00 & .70 & .04 & .16 & .18 & .17 & $.39 * *$ \\
\hline Training Composite & 24.43 & 4.04 & .19 & $.28 * *$ & $.25 *$ & $.26^{*}$ & $.42 * *$ \\
\hline Alpha & & & .78 & .89 & .73 & .85 & .79 \\
\hline $\begin{array}{l}\text { Mean } \\
\text { (SD) }\end{array}$ & & & $\begin{array}{c}4.22 \\
(.39)\end{array}$ & $\begin{array}{c}4.30 \\
(.41)\end{array}$ & $\begin{array}{c}3.74 \\
(.47)\end{array}$ & $\begin{array}{l}4.02 \\
(.48)\end{array}$ & $\begin{array}{l}4.10 \\
(.42)\end{array}$ \\
\hline
\end{tabular}


The correlations between the training composite and the five factors were significant, with the exception of agreeableness $(r=.19, N=81, n s)$. As predicted, conscientiousness $(r=.28, N=81, p<.05)$, extraversion $(r=.25, N=81, p<.05)$, and openness to experience ( $r=.42, N=81, p<.05$ ) were all significant predictors of performance. The unexpected result was that emotional stability was also a significant predictor of training performance $(r=.26, N=81, p<.05)$.

\section{Table 4}

Intercorrelations among training performance variables

\begin{tabular}{|c|c|c|c|c|c|c|c|c|c|}
\hline & 1 & 2 & 3 & 4 & 5 & 6 & 7 & 8 & 9 \\
\hline 1. Attendance & - & .06 & -.18 & -.16 & -.22 & -.16 & -.09 & .06 & -.15 \\
\hline 2. Participation & & - & $.47 *$ & $.33^{*}$ & $.38 *$ & $.50 *$ & $.58^{*}$ & $.40^{*}$ & $.42 *$ \\
\hline 3. Voice & & & - & $.42 *$ & $.45^{*}$ & $.71^{*}$ & $.71^{*}$ & $.48^{*}$ & $.68 *$ \\
\hline 4. Coding & & & & - & $.68^{*}$ & $.59 *$ & $.42 *$ & $.45^{*}$ & $.73 *$ \\
\hline 5. Probing & & & & & - & $.69 *$ & $.52 *$ & $.41^{*}$ & $.75^{*}$ \\
\hline 6. Persuade & & & & & & - & $.60 *$ & $.49^{*}$ & $.78^{*}$ \\
\hline 7. Personality & & & & & & & - & $.50 *$ & $.62 *$ \\
\hline 8. Strategy & & & & & & & & - & $.46 *$ \\
\hline 9. Overall & & & & & & & & & - \\
\hline
\end{tabular}

* Correlation is significant at the 0.01 level (2-tailed). $N=82$

Table 5

Factor Rotation Pattern Matrix

\begin{tabular}{lcc}
\hline & Factor 1 & Factor 2 \\
\hline Attendance/Punctuality & .418 & -.901 \\
Class Participation & $\mathbf{. 8 6 9}$ & -.383 \\
Voice Skills & $\mathbf{. 7 6 8}$ & .063 \\
Coding & $\mathbf{. 4 7 8}$ & .444 \\
Probing and Clarifying & $\mathbf{. 5 0 7}$ & .473 \\
Persuading & $\mathbf{. 7 2 1}$ & .251 \\
Personality & $\mathbf{. 8 6 3}$ & -.098 \\
Advanced Strategies & $\mathbf{. 8 2 0}$ & -.249 \\
Overall Rating & $\mathbf{. 6 7 2}$ & .358 \\
& & \\
Eigenvalues & 4.83 & 1.14 \\
(Variance explained) & $\mathbf{( 5 4 \% )}$ & $(12.68)$ \\
Alpha & .89 & N/A \\
\hline
\end{tabular}




\section{Discussion}

The results provide support for the validity of personality for selecting employees into this outbound call center position. Three of the five personality variables (conscientiousness, agreeableness, and emotional stability) predicted objective job performance and four of the five personality variables predicted training performance (agreeableness was not significant). These results also confirm the findings by Mount, Barrick, and Stewart (1998) that conscientiousness, agreeableness and emotional stability predict performance in jobs with a significant amount of interpersonal interaction. This study furthers the findings by Mount, Barrick, and Stewart (1998) by supporting the generalizability of their results to objective performance measures. The significant findings with the objective measure are encouraging since objective data can be affected by a number of factors that are not related to performance, and these factors can attenuate validity results.

For the training performance, the results reinforce the findings by Barrick and Mount (1991) that conscientiousness, openness to experience, and extraversion predict training performance. The present study also found that emotional stability was related to training performance, which was not found by Barrick and Mount (1991).

The objective criterion used in the first sample represents both a strength and a limitation of the current study. On the positive side, objective criteria are often difficult to identify and collect, and therefore are less frequently utilized in selection research than supervisory ratings (see Barrick \& Mount, 1991). Additionally, objective performance measures are often well accepted by client organizations because of their obvious business relevance. Conversely, objective performance data can be affected by a number of factors in the environment that are out of the control of the incumbent. Further, the objective measure used in this study (accepts divided by the sum of accepts and refusals), although identified as the most accurate measure of performance by the sponsoring organization, captures only one aspect of performance. Future studies in outbound call center environments might want to include supervisor and/or peer performance ratings that capture a broader range of relevant performance factors.

Future research might consider increasing the breadth of the criterion by adding citizenship performance. Borman, Penner, Allen, and Motowidlo (2001) define citizenship performance as behaviors that contribute positively to the work place environment and enhance workers' task performance. The importance of these behaviors has been demonstrated by a number of studies that found a relationship between citizenship behaviors and productivity (e.g., Podsakoff, Ahearne, \& MacKenzie, 1997). Future research may consider extending not only the criterion domain, but the predictors as well. For example, a study could incorporate cognitive and behavioral predictors to better capture the breadth of the criterion space.

Despite these limitations, this study's results support the usefulness of the Big Five in predicting job performance in an outbound call center position. The finding that personality correlated with performance across samples and criteria provides strong support for the operational use of personality for selecting outbound call center representatives in the sponsoring organization. 


\section{References}

Abraham, J. D. \& Morrison, J. D., Jr. (2002). Performance perspectives inventory: PPI technical manual, version b1.3. Tulsa, Oklahoma: A \& M Psychometrics, LLC. Available from http://www.ppicentral.com.

Abraham, J. D. \& Morrison, J. D., Jr. (2003a). Relationships between the performance perspectives inventory's conscientious scale and job performance of corporate security guards. Applied H.R.M. Research, 8 (1), 45-48.

Abraham, J. D. \& Morrison, J. D., Jr. (2003b). Relationships between the performance perspectives inventory's selling scale and job performance of real estate agents. Applied H.R.M. Research, 8 (1), 45-48.

Barrick, M. R., \& Mount, M. K. (1991). The big five personality dimensions and job performance: A meta-analysis. Personnel Psychology, 44, 1-26.

Barrick, M. R., Mount, M. K \& Judge, T. A., (2001). Personality and performance at the beginning of the new millennium: What do we know and where do we go next? International Journal of Selection \& Assessment, 9 (1-2), 9-30.

Borman, W. C., Penner, L. A., Allen, T. D., \& Motowidlo, S. J. (2001). Personality predictors of citizenship performance. International Journal of Selection and Assessment, 9 (1-2), 52-69.

Costa, P. T., Jr., \& McCrae, R. R. (1992). Professional manual, revised NEO Personality Inventory (NEO-PIR) and NEO five-factor inventory(NEO-FFI). Odessa FL: Psychological Assessment Resources.

Ghiselli, E. E. (1973). The validity of aptitude tests in personnel selection. Personnel Psychology, 26, 461-477.

Guion, R. M. \& Gottier, R. F. (1965). Validity of personality measures in personnel selection. Personnel Psychology, 18, 135-164.

Hogan, J. \& Holland, B. (2003). Using theory to evaluate personality and jobperformance relations: A socioanalytical perspective. Journal of Applied Psychology, 88 (1), 100-112.

Hurtz, G. M. \& Donovan, J. J. (2000). Personality and job performance: The big five revisited. Journal of Applied Psychology, 85 (6), 869-879.

Lodato, M., Zickar, M., and Fuller, J. (2004, April). Exploring the Dark Days of Personality Testing in Industry. Presented at the $19^{\text {th }}$ annual conference of the Society for Industrial-Organizational Psychologists, Chicago, Illinois.

Morrison, J. D., Jr. \& Abraham, J. D. (2003). Relationship between the performance perspectives inventory's selling scale and job performance of real estate agents. Applied H.R.M. Research, 8 (2), 85-88.

Morrison, J. D., Jr. \& Abraham, J. D. (2004). Relationship between the performance perspectives inventory's leadership scales and job performance of quick service restaurant managers. Applied H.R.M. Research, 9 (1), 31-34.

Mount, M.K. \& Barrick, M. R. (1995). The Big Five personality dimensions: Implications for research and practice in human resources management. Research in Personnel and Human Resources Management, 13, 153-200. 
Mount, M. K., Barrick, M. R., \& Stewart, G. L. (1998). Five-Factor Model of personality and performance in jobs involving interpersonal interactions. Human Performance, 11(2-3), 145-165.

Podsakoff, P. M., Ahearne, M. \& MacKenzie, S. B. (1997). Organizational citizenship behavior and the quantity and quality of work group performance. Journal of Applied Psychology, 82 (2), 262-270.

Salgado, J. F. (2003). Predicting job performance using FFM and non-FFM personality measures. Journal of Occupational and Organizational Psychology, 76, 323-346.

Salgado, J. F. (1998). Big five personality dimensions and job performance in army and civil occupations: A European perspective. Human Performance, 11, 271-288.

Schmidt, N., Gooding, R. Z., Noe, R. A., \& Kinch, M. (1984). Meta-analyses of validity studies published between 1964 and 1982 and the investigation of study characteristics. Personnel Psychology, 37, 407-422.

Schmidt, F. L. \& Hunter, J. E. (1998). The validity and utility of selection methods in personnel psychology: Practical and theoretical implication of 85 years of research findings. Psychological Bulletin, 124, 262-274. 